DOI: https://doi.org/10.24867/08CG07Tris

\title{
ULOGA PROJEKT MENADŽERA I NOVIH TEHNOLOGIJA U SAVREMENIM PROJEKTIMA GRAĐEVINSKE INDUSTRIJE
}

\section{THE EFFECT OF PROJECT MANAGERS AND NEW TECHNOLOGIES IN MODERN CONSTRUCTION INDUSTRY PROJECTS}

\author{
Marko Tris, Fakultet tehničkih nauka, Novi Sad
}

\section{Oblast - GRAĐEVINARSTVO}

Kratak sadržaj - Uloga projekt menadžera $i$ novih tehnologija u savremenim projektima. Analizirani efekti saradnje projektnog tima. Predstaljanje mogućnosti pojedinih platformi i aplikacija za rad u BIM okruženju.

Ključne reči: BIM, BIM softver, Projekt menadžer, projektni tim, dizajn, model

Abstract - The role of project managers and modern technologies in modern projects. Analyzed effects of project team collaboration. Featured capabilities of individual platforms and applications for work in the BIM environment.

Keywords: BIM, BIM software, project manager, project team, design, model

\section{UVOD}

Novo doba savremenih tehnologija i način rukovođenja za posledicu ima ubrzan protok informacija i kraći period da se izvede projekt. Nove tehnologije prenose rad na projektu iz papirnog oblika i formulara u digitalni oblik koji je dostupan na privatnom serveru ili internetu. Građevinska industrija nalazi se $u$ tranziciji iz tradicionalnog radnog ambijenta, načina poslovanja i ugovaranja, prilagođavajući se novim tehnologijama, novom obliku kontrolisanja i rukovođenja projekta.

Cilj je da predstavi, objasni i pokaže efekti koje donose nove tehnologije i novi načini rukovođenja. Akcenat će biti na figuri koja rukovodi projektom - projekt menadžer i novim tehnologijama kao što je BIM okruženje. Projekt menadžment poprima ulogu facilitatora $\mathrm{u}$ projektnom timu, praćenjem zacrtanih rokova, obima posla, okvira budžeta i kvaliteta izvedenih radova. Samim tim njegova uloga kao lidera i menadžera projekta je sa ciljem da motiviše učesnike u projektu kako bi se ispunili zacrtani planovi i ciljevi projekta.

Nove tehnologije su uglavnom vezane za internet i nove aplikacije kao što su Građeni Informacioni Model ili popularnije BIM (eng. Building Information Modeling). Predstavljeni su benefiti novih tehnologija po članove projektnog tima.

\section{NAPOMENA:}

Ovaj rad proistekao je iz master rada čiji mentor je bio prof. dr Igor Peško.

\section{PROJEKT MENADŽER I BIM}

\subsection{Projekt menadžer}

Planiranje, monitoring i kontrola svih aspekta projekta i motivacija pojedinaca uključenih $u$ isti, sa ciljem da se ostvari projektni cilj unutar dogovorenog roka za izgradnju, u okviru budžeta i zadovoljavajućeg kvaliteta, zadatak je projekt menadžera. Iako definicija uključuje kriterijum vremena, troškova i performansi, ipak akcenat treba da bude na motivaciji. Projekat neće biti uspešan ukoliko svi ili bar većina učesnika, koji su kompetentni, ne budu motivisani da zadovoljavajuće posao završe. Pored motivacije, neke od osobina projekt menadžera su liderstvo i komunikacija.

Za kvalifikacije projekt menadžera potrebno je da ima određene atribute. Značajno praktično znanje u građevinarstu kako bi se razumeo radni proces na gradilištu. Sledeće je da projekt menadžer treba da ima sposobnost da vidi širu sliku i predvidi buduće aktivnosti, kao i potencijalne problema koje treba da izbegne, stanje i nabavka potrebnom materijala na gradilištu, prepoznavanje izmene u radu na nekim pozicijma.

Projekt menadžer treba da ima karakteristiku da radi skladno sa drugim ljudima, da radi nekad pod pritiskom i iznalazi rešenja. Ipak menadžer ne može da uradi sve sam, potrebno je da ima odgovarajući tim ljudi iza sebe. $\mathrm{Na}$ slici 1. data je hijerarhijska lestvica unutar projektnog tima, investitor i kao njegov predstavnik, projekt menadžer sa konsultantima.

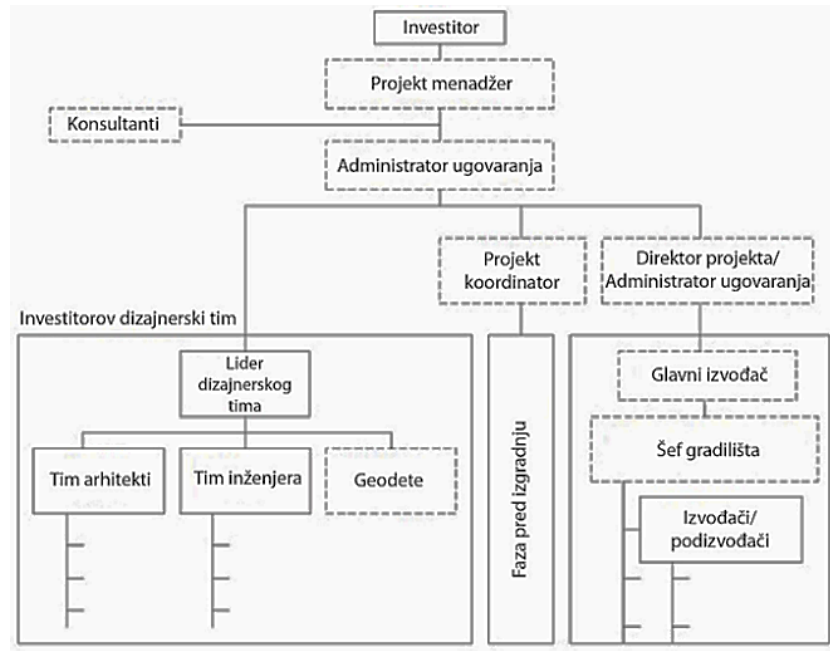

Slika 1. Članovi projektnog tima [1]

Administrator projekta facilitira projektni tim i obrađuje informacije. Projektni tim se deli na dizajnerski tim koji 
može biti izdeljen na tim arhitekti, inženjera i dobavljači. Sa druge strane je glavni izvođač koji ima svog menadžera projekta na gradilištu, ali i odgovoarajuće podizvođače ukoliko je potrebno. Koordinator projekta bavi se u ranoj pripremnoj fazi usmeravanjem i vodjenjem projekta. Pored menadžerskih sposobnosti, u projekt orjentisanom okruženju dobro liderstvo je veoma poželjna osobina projekt menadžera. Liderstvo se može opisati kao sposobnost da inpsiriše, ubedi i utiče na druge da pokrenu odgovarajuće akcije prema definisanom cilju. Obično za lidere se kaže da rukovode projektom. Liderstvo nije isto što i menadžment. Liderstvo je zasnivano na motivaciji, uticaju i davanjem dobrih primera timu ili pojedincu, dok menadžment fokusiran na administrativne $\mathrm{i}$ organizacione delove projekta i kompanije.

Lideri su fokusirani na viziju, misiju, ciljeve, dok menadžeri na produktivnost i efikasnost. Menadžeri rešavaju problem kako bi drugi radili njihov posao, dok lideri inspirišu i motivišu druge da nađu sami rešenje [2]. Samim tim dobar projekt menadžer treba da kombinuje liderske i menadžerske osobine za benefit projekta. Iako su lideri i menadžeri različiti, u organizaciji su potrebni oboje. Menadžeri su potrebni da urade svakodnevne poslove, a lideri su kritično važni za inspiraciju zaposlenih i usmeriti dugoročno tok kompanije. Samim tim ključno za organizaciju jeste da bude pravilno vođena (lider) i upravljana (menadžer).

\subsection{Ciljevi i faze projekta}

Projektni ciljevi mogu biti predstavljeni kao na slici 2 . Smatraju se kao tri najvažnija cilja u projekt menadžmentu [3]:

1. Obim/kvalitet: obezbediti projektni okvir u skladu sa specifikacijama iz ugovora

2. Cena/budžet: obezbediti kompletan projekat u okviru budžeta

3. Vreme/rokovi: Završenje projekta u skladu sa planiranim rokovima

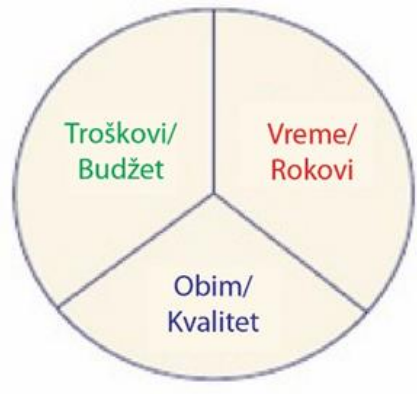

Slika 2. Ciljevi projekta [3]

Glavni koraci u projekt menadžmentu su početne ideje, planiranje, implementacija, monitoring/akcija i na kraju zatvaranje procesa. U građevinarstvu faze projekta se mogu u grubo podeliti na sledeće faze [4]: 1. Koncept i definisanje, 2. Dizajn, 3. Planiranje i organizacija, 4. Nabavka i izgradnja, 5. Monitoring i kontrola, 6. Zatvaranje i evaluacija projekta.

Na slici 3. prikazani su segmenti projekta i po redosledu nastajanja tokom faza projekta. Počeci se započinju željom investitora da sa svojim saradnicima formira koncept i zamisao projekta. Onda se sprovodi faza opravdanosti investicije, koja menja dati koncept i prilagodjava datim uslovima. Sa opravdanošću investicije može se početi sa planiranjem i inženjerskim projektovanjem projekta, sa čime se prelazi iz faze planiranja u izvođenje projekta. Vrši se nabavka materijala i izgradnja može početi sa sukcesivnom predajom radova kao projekat izvedenog stanja, čime se projekat završava.

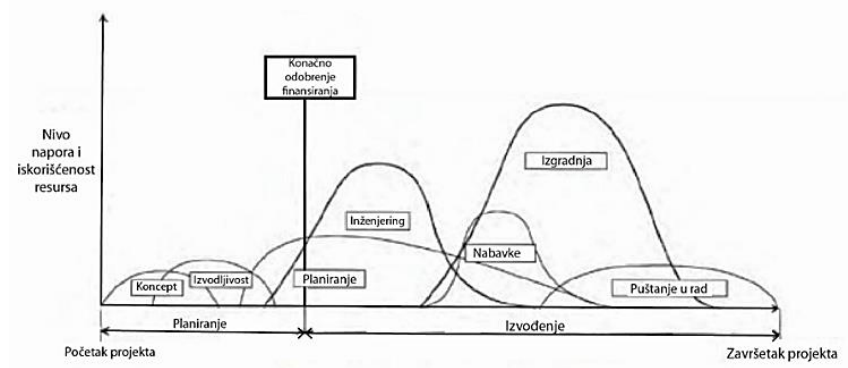

Slika 3. Dinamika projekta [5]

\subsection{Building Information Modeling (BIM) (Građenje Informacionog Modela)}

Building Information Modeling (BIM), u prevodu Građenje Informacionog Modela, je filozofija koja na velika vrata ulazi u polje arhitekture, građevinarstva i industrijskog inženjerstva.

BIM omogućava razmenu informacija i podataka između svih članova i učesnika u projektu tokom celokupnog trajanja. Obezbeđuje platformu za conciznu, strukturnu i efikasnu obradu informacija, da bi se donosile pravovremene odluke tokom svih faza projekta. BIM je projekt, ali i simulator procesa. Projekt BIM je baza podataka informacija o objektu koji može biti korišćen tokom kompletnog proizvednog veka. Kroz obradu informacija, dizajn, nabavku, troškove, ugovore, dostavke na gradilište i ugradnju, stanje posmatrane aktivnosti, predaje radove i informacije o održavanju objekta kao deo operativnog menadžmenta jesu samo neke od mogućnosti BIM okruženja. Planiranje i realizacija BIM-a je veoma sličan planiranju i realizaciji stvarnog građevinskog projekta. Simulacioni proces će paralelizovati stvarni proces, što je glavni razlog zašto je BIM tako efikasan alat.

Izrada BIM-a je zahtevna i uključuje mnoštvo ljudi da budu u projektnom timu, koji su često bave različitim vrstama posla koje treba da rade zajedno na datom projetku. To stvara potencijalne probleme u komunikaciji na prvi pogled, ali često takvo udruživanje za posledicu imaju kvalitetniji projekat i veoma bogato iskustvo za ceo tim koji radi na tom projektu. Korišćenjem 3D dizajn fajlova u programima kao što su Revit, Bentley ili Tekla, mogu se izvlačiti specifikacije materijala, dokumenti $u$ wordu i pdf-u, informacije o ceni koštanja, fajlovi sa tehničkim informacijama i druge informacije koje mogu biti dodate u bazu podataka.

Fundamentalna karakteristika BIM-a je potenciranje povratne sprege u komunikacije među članovima tima. Samim tim i evolucija modela i relevantnih projektnih informacija je ciklična, tj. interativna. Samim tim što na projektu rade ljudi iz različitih grana industrije, dobijene informaciju proširuju okvir i dubinu projekta, davajući mu dobar temelj za ko-operaciju. Kod integrisanog projekta, učesnici u projektu treba da razumeju kako da koriste 3D/BIM, za razliku od 2D crteža, može da se koristi za 
koordinaciju na terenu, procene, planiranje i projekt menadžment. Cena izrade modela može biti simbolična u odnosu na potencijalne uštede pri greškama u izradi, kraćim periodom za završetak projekta, bolja iskorišćenost prefabrikacije za potrebe gradilišta, manje radnika na gradilištu, kao i bolja saradnja unutar projektnog tima.

Dve važne karakteristike BIM-a su protok u razmeni podataka među članova i razmena podataka između softverskih aplikacija. BIM igra važnu ulogu na polju integracije informacija i operabilnosti od virtulene platforme do gradilišta. BIM se može koristiti za: vizuelni prikaz dizajna, planiranje gradilišta i opreme, 4D planiranje i praćenje, 5D procena troškova, integracija podizvođača i dobavljača, sistemske koordinacije, prefabrikacija, operativnost i održavanje.

Dobar dizajn je direktno povezana sa kvalitetom informacija. Dostupnost informacija u odgovarajućem vremenu i potrebnom formatu daju dobar temelj za pravovremene odluke. Kreiranje virtuelnog 3D modela često predstavlja izazov jer se na projektu prepliću članovi tima iz različitih branši. Svi delovi kompozitnog modela mogu se koordinisati da bi se izbegli potencijalni konflikti (više objekata koji zauzimaju isto mesto) kako bi se isti identifikovali i rešili. Ovi procesi se nazivaju kleš detekcija (eng. Clash - srb. Sudar).

Neki softveri imaju opciju praćenja izgradnje i simulacije modela. Samim tim može se prikazati u kojoj je fazi određeni materijal, određujući njegov status. Mogući statusi su ne urađeni, fabrikacija, transport, skladišten na gradilištu, procenat ugrađenosti i ugrađen u objektu. U opisu se može upisati ime dobavljača, pozicija ugradnje, vreme ugradnje i mnogi drugi relevantni podaci.

Dodavanjem dimenzija u smislu abstraktnih informacija može se dobiti punija slika za razumevanje projekta. Generalno se misli na geometrijske dimenzije i abstraktnih sistema [6], gde 2D označava površinu, 3D prostornu dimenziju (dužina, širina $\mathrm{i}$ visina), 4D prostor dodaje vreme kao dimenziju, dok 5D prostor uključuje cenu koštanja. Sa nD se odnosi na bilo koju drugu vrstu količine dodatu u predhodni miks kao što je energetska analiza, održivi dizajn ili informacije o operativnom menadžmentu. Dimenzije koje postoje su: a) 3D: Trodimenzionalni render modela, b) 4D: Analiza vremena, c) 5D: Analiza troškova, d) 6D: Procena održivosti i operativni menadžment.

4D BIM obuhvata ekstra dimenziju u projektnom informacionom modelu $\mathrm{kroz}$ vremensku odrednicu aktivnosti. Podatak je zadat u okviru komponente $\mathrm{u}$ modelu u vidu parametra. Sa zadatom informacijom može se tačno prikazati u programu i vizuelno predstaviti redosled gradnje objekta po sekvencama. Informacije vezane za informacije mogu da sadrže i vreme naručivanja materijala, koliko vremena je potrebno da se element ugradi ili izgradi, vreme koje je potrebno da element bude operativan/očvrsne/odnegovan, moment kad komponenta treba da bude ugrađena, kao i uticaj na druge elemente $\mathrm{u}$ projektu. Alternativni pristup projektnom planiranju i projekt menadžmentu je da se razvije vizuelna reprezentacije objekta i prikaže sled građevinskih aktivnosti kroz vizuelni prikaz u svakom trenutku vremena. Rad na ovaj način umnogome pogoduje planiranju poslova da bi se doprinelo bezbednosti, logistika i efikasno sprovođenje radova. Moguće je optimizovati vreme za naručivanje materijala i zalihe na gradilištu, čime se prati celokupni projekat i naredne aktivnosti kroz vreme.

Unošenjem informacija o ceni materijala, opreme i radne snage unutar virtuelnog modela je suština analize cena $\mathrm{i}$ 5D sistema. Peta dimenzija BIM modela se odnosi na kontrolisanje budžeta i analizu troškova. Ova informacija omogućava menadžerima da eksportuju količine iz modela, ubacivanjem cena koštanja radne snage i materijala dobija sve sveobuhvatna cena date komponente. Model omogućava vizuelno predstavljanje komponente i cene koštanja elementa, praćenjem izmena $\mathrm{u}$ statusu elementa u toku procesa, kao i automatsko brojanje koliko elemenata se nalazi na projektu. Jedna od prednosti ekstrakcije cena iz informacionog modela je mogućnost da se informacija može menjati u bilo koje vreme projekta kako bi se dobila nova informacija i realan protok novca. Realan plan troškova omogućava dizajnerskom timu da osmisli realan budžet. Samim tim menadžeri su uključeni od početka projekta, omogućava preciznije izveštaje o ceni koštanja u ranoj fazi projekta.

Operativna kontrola i održavanje su dve važne stavke operativnog menadžmenta koje su obuhvaćene u 6D BIM modelu. BIM okruženje menja pristup operativnog menadžmenta po pitanju dokumentacije, održavanja i analiza. Departman operativnog menadžmenta korišćenjem BIM tehnologija smanjuje operativnu kontroli i troškove održavanja, omogućavajući precizniji kontrolni sistem, omogućavajući efektivnije usluge za korisnike objekta. Integrisanim informacionim BIM sistemom mogu se koristiti napredne funkcije za operativni i održivi rad objekta. Postupci su usmereni na prevenciju otkazivanja uređaja kako bi se poboljšala bezbednost, efikasnost i pouzdanost. Neplanirani troškovi pri otkazivanju uređaja mogu izazvati velike troškove zbog neadekvatne i pravovremene reakcije.

Operativnost i održavanje objekta u operativnom menadžmentu mogu se podeliti u dve kategorije: prevencija i korekcija. Prevencija se bazira na rutinske planove održavanja objekta, dok korekcija se odnosi na grešku ili kvar unutar operativnog sistema objekta. BIM tehnologija može pratiti različite vrste parametara kao što su, kao što su lokacija komponente, praćenje izveštaja parametara u realnom vremenu, istorija održavanja za pojedine segmente, vreme sledećeg redovnog servisa ili kontrole su samo neki od dobrobiti BIM tehnologije za operativni menadžment. Efikasnim prikupljanjem informacija ugrađenih elemenata za posledicu ima bolje razumevanje performansi elemenata u sveobuhvatnom sistemu, kako bi se razvila strategija optimalne upotrebe energije za održivi rad objekta.

\subsection{D simulacija}

Projektnim zadatkom predstavljena je 4D simulacija stambenog objekta. Spojem 3D modela rađenog u revitu (slika 4.), spiskom aktivnosti iz eksela spaja se u Navisworks Timeliner gde se dobije sekventni redosled gradjenja. U 3D modelu pojedini elementi su rastavljeni na segmente kako bi se dobio precizniji način izvođenja radova. U ekselu su izdeljene aktivnosti prema predstavljenim elementima u 3D modelu. Izdeljene aktivnosti i elementi u 3D modelu se potom povezuju Na visworksu 
kako bi se napravio tačan sled radova koji će prikazan u animaciji. Animacija je video zapis po danima gde se prikazuju početak i završetak pojedine aktivnosti. Na početku aktivnosti element koji se gradi poprima providno-zelenu boju i po završetku aktivnosti element dobija svoj konačni izgled.

Video zapis je moguće renderovati kako bi se dobio model sa visokom rezolucijom završne obrade površine elementa, koji bliži realnom izgledu objekta.

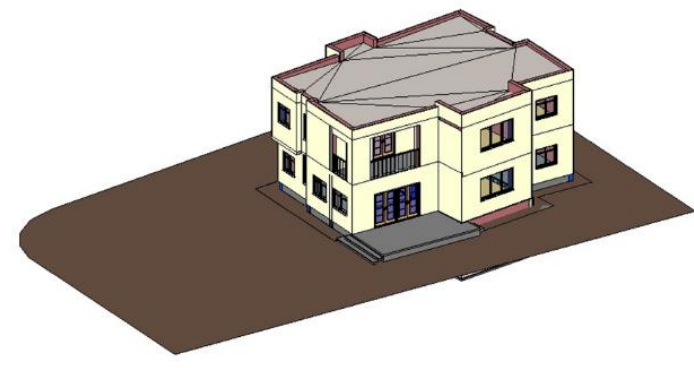

Slika 4. Revit 3D model stambenog objekta

\section{ZAKLJUČAK}

Novi način odnosa prema projektu, tesnijom saradnjom unutar projektnog tima, faktor koji povezuje, rukovodi i kontroliše ceo proces je projekt menadžer. Njegova uloga je da motiviše tim, ali i da pokaže liderske i menadžerske sposobnosti da bi se projekt uspešno sprovodio. Projekt menadžer formira ambijent i nivoe komunikacija unutar projektnog tima. Kompleksnošću projekta, komunikacija i saradnja čini značajan segment ka uspehu.

Dobijanjem povratne informacije u odnosu na donesene odluke, može se videti šira slika i preduprediti neplanirane situacije. Samim tim projekt menadžer planira produktivnost, vreme utrošeno na date aktivnost, raspolaže i optimizuje raspoložive resurse, sistemom nabavke, procenjuje rizik, preventivne ili korektivne akcije. Projekt menadžer današnjice predstavlja rukovodioca projekta koji uz pomoć novih tehnologija prikuplja, analizira i obrađuje dostupne informacije.

Obradom infomacije, sprovodi adekvatnu akciju imajući u vidu da celokupni projekat bude unutar budžeta, u planiranom roku i zadovoljavajućeg kvaliteta.

BIM nije samo alat ili softver već pretočena aktivnost pojedinca koja pokreće mnoge procese u projektu. Veliki investitori razvijaju ugovore i detaljna uputstva za njihov projekat korišćenjem BIM okruženja. Razvijaju se nove sposobnosti, BIM alati postaju široko zastupljeni $u$ projektnim biroima $i$ na gradilištu. Nedostatak profesionalno treniranog kadra, a nadolazeći novi softveri koji se bore za primat na dinamičnom tržištu, otvaraju mnoge mogućnosti za građevinsku industriju i druge profesije. Još uvek BIM je filozofija koja se razvija i nadgrađuje.

Kako developeri budu razvijali, a i tržište bude pokazalo interes za novim tehnologijama, menjaće se i način na koji se pristupa građenju objekta. BIM će značajno uticati na prefabrikaciju objekta, manje dokumentacije i štampanja, manje grešaka u modelu, samim tim i na gradilištu, manje otpada i bolja produktivnost.
Sa boljom analizom i iznalaženjem alternativnih opcija, manje klejmova će biti potrebno da bi se budžet zadržao u okviru i planirani rokovi završeni na vreme. Ipak BIM nije rešenje za sve probleme - prilično je moguće napraviti loš model po pitanju funkcionalnosti, konstrukcije i vrednosti, kao što je moguće napraviti loš crtež, planiranje ili druge tradicionalne forme informacija [6]. U budućnosti sve više će se koristiti detekcija sudara, 3D printanje modela, simulacija, lasersko skeniranje, procene troškova (5D) i analiza održivosti.

Digitalizacijom građevinskog sektora, informacije bi se znatno brže delile, kolaboracija i komunikacija se produbljuje među projektnim timovima, a projekat postaje objedinjen, bolje praćen i kontrolisan.

Ukoliko je korišćen efektivno, BIM model može biti virtuelna replika izvedenih objekata. Softverska i hardverska istraživanja smanjuju razliku između virtuelnog predstavljanja i fizički izvedenih aktivnosti. Pravilno rukovođenje projektom (projekt menadžment) i nove tehnologije doprinose boljoj organizaciji rada koja za cilj ima kvalitet, praćenje budžeta i rokova. Ovo su uzbudljiva vremena za projekt menadžere, arhitekte, inženjere i za celu građevinski sektor.

\section{LITERATURA}

[1] Eugenio Pellicer, Víctor Yepes, José C. Teixeira, Helder P. Moura, Joaquín Catalá - Construction Management (2013)

[2] Albert Lester - Project Management, Planning, and Control (2014)

[3] Saleh Mubarak- Construction Project Scheduling and Control (2015)

[4] S. Keoki Sears, Glenn A. Sears, Richard H. Clough, Jerald L. Rounds, Robet O. Sergner, Jr. - Construction project managment - A practical guide to field construction management (2008.)

[5] Hira N. Ahuja, S. P. Dozzi, S. M. Abourizk - Project management - Techniques in Planning and Controlling Construction Projects (1994)

[6] Webster's New World College Dictionary

[7] Duncan Cartlidge - Construction Project Manager's Pocket Book (2015)

\section{Kratka biografija:}

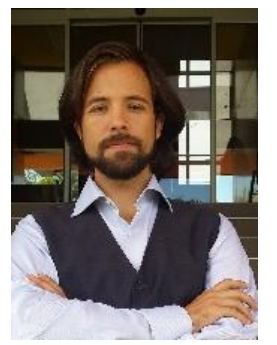

Marko Tris rođen je u Dubrovniku 1988. god. Svoje interesovanje je posvetio ekološkoj i održivoj gradnji. Master rad na Fakultetu tehničkih nauka na Departmanu za građevinarstvo i geodeziju odbranio je 2019.god.

kontakt: trismarko@gmail.com 